\title{
Effect of storage conditions and duration on the potency of Neem (Azadirachta indica A. Juss) seeds as a home-made Insecticide
}

\author{
H.A.F. El Shafie ${ }^{1}$ and A.A.M. Almahy ${ }^{2}$ \\ ${ }^{* 1}$ Department of crop protection, University of Khartoum, 13314 Shambat, Khartoum, Sudan \\ ${ }^{2}$ Sudanese Standards and Metrology Organization, Baladia Street, Khartoum-Sudan \\ "Corresponding author's e-mail: elshafie62@yahoo.com
}

\begin{abstract}
This work was carried out to investigate the effects of grinding, storage conditions and duration on the bio-efficacy of neem seeds as a home-made insecticide against the red flour beetle Tribolium castaneum. Samples of neem seeds (intact and ground) were kept in small jute sacks and stored in the sun, refrigerator $\left(4^{\circ} \mathrm{C}\right)$, and room temperature $\left(28 \pm 2^{\circ} \mathrm{C}\right)$ for two, four and six weeks in each condition. After the respective storage period, a water extract (5\%) was prepared and sprayed topically on the $3^{\text {rd }}$ instar larvae of the beetle as well as on the pupal stage. A significant mortality of $62.83 \%$ resulted from the neem seeds stored in the refrigerator on the $7^{\text {th }}$ day of exposure. The seeds stored in the sun caused a mortality of $48.49 \%$. The water extract from the seeds which were stored at room temperature, resulted in significantly high cumulative larval mortality of $50.30 \%$. The efficacy of neem seeds kept in the sun was negatively affected and correlated with the length of storage period. However, the efficacy of the neem seeds stored in the refrigerator was increased with storage time. The pupal mortality due to spraying with water extract from neem seeds stored in the sun, refrigerator and room temperature was 49.67 , 68.12 and $69.43 \%$ respectively. The mortality in the control (water treatment) was $7.33 \%$. The results indicated that grinding of neem seeds before storage seems to have no effects on their efficacy.
\end{abstract}

Keywords: Tribolium castaneum, Azadirachtin, bio-efficacy, Sudan, Larval mortality, neem seeds

\section{INTRODUCTION}

Neem's greatest potential usefulness is in the subsistence agricultural systems of the tropics (Jenkins, et al. 2003). The number of neem trees in Sudan is estimated to be more than one million (Badi et al., 1989, Förster and Moser, 2000). The neem fruits are usually available in Sudan in the period from June to August each year, while the main cropping season of vegetable production extends from November to March. The scarcity of good quality neem seeds should have to be overcome if the neem seeds are to be used in the management of vegetable pests. Fruits seasonality, lack of technical know-how on the side of farmers on the proper storage and post-harvest handling of neem seeds, are the main obstacles facing the practical application of home-made neem biopesticides for the management of important vegetable pests in Sudan (Elshafie, 2001). The Azadirachtin content of the neem seeds collected from different ecological zones in Sudan ranged between $1.08-2.3 \mathrm{mg} / \mathrm{g}$ and 0.48 $3.09 \mathrm{mg} / \mathrm{g}$ in seasons 2001 and 2002 respectively and rainfall, soil type, latitude and altitude were the main factors behind these variations (EITeraifi, 2004). Ermel (1995) estimated the Azadirachtin content from neem seeds collected from Sudan to be in the range of $0.2-0.5 \%$. Schmutterer and Ascher (1987) reported that Azadirachtin, the main active ingredient in neem seeds, was fairly stable until the temperature reached $65^{\circ} \mathrm{C}$ and declined thereafter in the next higher degrees of temperature, when the seeds were exposed to different regimes of temperature. The diverse biological effects of the neem kernel extracts are phagodeterrent and repellent (Jacobson, et al. 1987, Ladd, et al., 1978), growth regulator (Leuschner, 1972; Schmutterer and Hübner, 2005). Stokes and Redfern (1982) reported that Azadirachtin content of neem seeds was reduced by $50 \%$ following days of exposure to sunlight. The UV light and sunlight destroy primarily the more polar substances, such as Azadirachtin and salannin and the relative humidity and temperature have a marked influence on the active constituents of neem seed kernels and their extracts (Schmutterer and Ascher, 1987). Photodegradation of Azadirachtin also occurs under field conditions, according to various reports 
(Ladd, et al.; Strokes and Redfern, 1982; Lange, 1984). Certain carriers and stabilizers have been used successfully to reduce degradation of Azadirachtin by heat in the laboratory (Kumar and Parmar, 1999) but, these are not readily available to subsistence farmers. In Sudan, growing of vegetables is increasing to meet the growing demand (Dabrowski et al. 1994). Polyphagous insects such as whitefly, aphids and African boll worm are considered as major pests inflicting economic damage on vegetables which are mainly produced during winter (Binyanson, 1997). Frequent use of synthetic insecticides, to manage these pests; lead to increase of production cost, a destabilization of the ecosystem as well as insect resistance (Dittrich et al. 1990). To reduce the cost of production for the poor farmers and to save the environment from the unwise use of chemical pesticides, the huge potential of the tree, Azadirachta indica should be exploited. Home- made insecticides, adapted for the farmers should be made as cheap, environmentally-friendly, and effective alternatives to the more costly synthetic chemicals for the management of the major vegetable pests. This work was carried out to investigate the effects of grinding, storage conditions and duration on the bioefficacy of neem seeds as a home-made insecticide against the red flour beetle, $T$. castaneum.

\section{MATERIALS AND METHODS}

Collection of neem seeds and preparation of samples: Neem seeds were hand-picked from mature disease-free trees in Shambat area, in Khartoum University campus July-August, 2008. They were depulped and thoroughly washed by hand to remove the pulp that if left would encourage growth of fungi. Seeds collection was done during the late fruit ripening season (July-August) when all fruits were yellow. The seeds were then shade-dried on jute mats and used for different treatments. To study the effect of storage conditions, the collected seeds were divided into two lots, one lot was pulverized and the other was left as intact seeds. The lot of intact seeds and powder were further subdivided each into three lots and each lot was kept under different conditions viz., sun, refrigerator and room temperature. Under all conditions of storage, the neem seeds were kept in small jute sacks that provided proper ventilation. Samples were taken from these lots after 2, 4 and 6 weeks to study the effects of storage duration. In case of intact seeds, they were pulverized before being used to prepare the water extract.
Insect culture: The red flour beetle, $T$. castaneum is a member of the most species-rich eukaryotic order, a powerful model organism for the study of generalized insect development, and important pest of stored agricultural products. The beetle is omnivorous and has evolved the ability to interact with a diverse chemical environment, as shown by large expansions in odorant and gustatory receptors, as well as P450 and other detoxification enzymes (Anon., 2008). The insect has a short life cycle, high fecundity and can be easily reared in the laboratory on a variety of agricultural products (Sokoloff, 1977). For the above mentioned reasons, the red flour beetle was chosen for the bioassay test. Adult beetles were brought from infested sorghum grain in the local market and were reconditioned and reared in the laboratory, for at least three generations before they were used in the different experiments. The beetles were reared on sorghum grains in 1-liter jars in a controlled environment at

$28 \pm 1^{\circ} \mathrm{C} ; 75 \pm 5 \mathrm{RH}$; photoperiod of $12: 12$ (L: D) h.

Preparation and application of the neem water extract (NWE): To prepare the neem water extract, the intact neem seeds were pulverized using an electric kitchen blender. $50 \mathrm{~g}$ of the neem powder were put into $1 \mathrm{~L}$ of water $(5 \%)$ and agitated thoroughly with a glass rod. The mixture was left overnight and sieved through a fine mesh cloth to obtain a uniform extract and to remove coarse particles that would otherwise close the spray nozzle. In all experiments, the extract was topically applied on the test insects using a hand-hold sprayer.

Bioassay test: The bioassay was conducted under laboratory conditions of $28 \pm 2^{\circ} \mathrm{C}$ temp. and $75 \%$ relative humidity, 12:12 light : dark photoperiods. Ten $3^{\text {rd }}$ instar larvae of $T$. castaneum were put in a Petri dish and were considered as experimental unit. Three replicates were used per each treatment. The water extracts prepared from neem seeds (intact and ground) which were stored at different storage conditions and for different durations, were topically applied on these test insects. Mortality per cent of larvae was recorded from the $1^{\text {st }}$ up to the $7^{\text {th }}$ day after exposing them to the extracts. Pupal mortality was also determined by using ten pupae per experimental unit and three replicates. Pupa that fails to transfer to adult was considered dead. These two parameters were used to evaluate the bio-efficacy of the test product.

Statistical analysis: Treatments were arranged in a completely randomized design and each treatment 
was replicated three times. The collected data was statistically analyzed by ANOVA and Duncan's Multiple Range Test was used for means separation.

\section{RESULTS}

The results of the bioassay test on the red flour beetle $T$. castaneum, reveal that the extracts form neem seeds (intact and ground) stored in the sun, refrigerator, and room temperature for 4weeks, caused significant mortality of the larvae compared with the control. The mortality per cent caused by the neem seeds and neem seed powder stored in the sun, was $49.05 \%$ and 47.93 respectively, while the samples stored in the refrigerator for the same period, caused significantly higher mortalities of $63.4 \%$ and $62 / 26 \%$ respectively. The efficacy of the seeds (intact) kept at room temperature reached $50.30 \%$, which was significantly higher than the efficacy of seeds stored in the sun. In case of storing the neem seeds either in the sun or the refrigerator, grinding seems to have no significant effects on the efficacy (Table 1). The data presented in table 2 indicate that there were significant differences among the treatments due to the duration of storage. The neem seeds stored in the refrigerator resulted in the highest mortality per cent of the test larvae $70.03 \%$, followed by the seeds stored at room temperature $53.30 \%$ and the seeds stored in the sun $50.11 \%$. In case of the latter, the efficacy decreased with increase of storage time while, the efficacy increased from $55.10 \%$ for the seeds stored only for 2 weeks to $70.03 \%$ for those kept for 6 weeks. The pupal mortality per cent due to spraying of pupae with water extract from neem seeds stored in the sun, refrigerator and room temperature was 49.67, 68.12 and $69.43 \%$ respectively, compared with $7.33 \%$ in the control (water treatment). There were significant differences among the treatments and the results demonstrated that the efficacy decreased with increasing storage time for the neem seeds stored in the sun and increased with storage time in case of the refrigerator (Table 3).

Table 1: Mean percentage mortality of Tribolium castaneum treated with neem extract prepared from neem seeds stored for 4 weeks in the sun, refrigerator, and room temperature

\begin{tabular}{|c|c|c|c|c|c|c|c|}
\hline \multirow{3}{*}{ Treatment } & \multicolumn{7}{|c|}{ Mortality percentage } \\
\hline & \multicolumn{7}{|c|}{ Days after treatment } \\
\hline & 1 & 2 & 3 & 4 & 5 & 6 & 7 \\
\hline NSS & 8.92 & 17.8 & 31.17 & 37.37 & 44.55 & 47.91 & $49.05 a$ \\
\hline NSPS & 13.34 & 23.36 & 37.83 & 43.4 & 46.75 & 47.90 & $47.93 a$ \\
\hline NSF & 18.90 & 31.12 & 52.23 & 60.02 & 62.26 & 63.38 & $63.40 \mathrm{~b}$ \\
\hline NSPF & 17.79 & 37.8 & 54.34 & 60.03 & 61.15 & 62.26 & $62.26 \mathrm{~b}$ \\
\hline NSRT & 10.03 & 16.73 & 26.77 & 36.80 & 43.50 & 50.20 & $50.30 \mathrm{ac}$ \\
\hline $\mathrm{CON}$ & 0.1 & 0.20 & 0.30 & 6.80 & 7.13 & 7.23 & $7.33 \mathrm{~d}$ \\
\hline
\end{tabular}

Means in a column followed by different letters are significantly different $(P<0.05$, Tukey test $)$

NSS $=$ Neem seeds stored in the sun

NSPS $=$ Neem seeds powder stored in the sun

$\mathrm{NSF}=$ Neem seeds stored in the refrigerator $\left(4^{\circ} \mathrm{C}\right)$

$\mathrm{NSPF}=$ Neem seeds powder stored in the refrigerator

NSRT $=$ Neem seeds stored at room temperature $\left(28 \pm 2^{\circ} \mathrm{C}\right)$

$\mathrm{CON}=$ Treated with water only 
Agric. Biol. J. N. Am., 2012, 3(10): 385-390

Table 2: Means percentage mortality of the $3^{\text {rd }}$ instar larvae of Tribolium castaneum treated with extracts from neem seeds stored at different storage conditions and for different periods of time

\begin{tabular}{|c|c|c|c|c|c|c|c|}
\hline \multirow{3}{*}{ Treatment } & \multicolumn{7}{|c|}{ Mortality percentage } \\
\hline & \multicolumn{7}{|c|}{ Days after treatment } \\
\hline & 1 & 2 & 3 & 4 & 5 & 6 & 7 \\
\hline NSS6 & 8.36 & 13.43 & 30.11 & 35.16 & 41.85 & 45.20 & $45.25 \mathrm{~b}$ \\
\hline NSS4 & 15.00 & 26.68 & 37.70 & 43.38 & 48.38 & 48.43 & $50.11 \mathrm{a}$ \\
\hline NSS2 & 20.06 & 21.70 & 36.70 & 43.37 & 46.73 & 50.08 & $50.12 a$ \\
\hline NSF6 & 20.00 & 44.16 & 60.00 & 66.67 & 67.20 & 70.03 & $70.03 \mathrm{c}$ \\
\hline NSF4 & 21.66 & 38.35 & 55.01 & 60.03 & 63.36 & 63.36 & $63.42 \mathrm{c}$ \\
\hline NSF2 & 13.36 & 23.36 & 45.03 & 23.38 & 55.06 & 55.08 & $55.10 d$ \\
\hline NSRT6 & 10.03 & 16.73 & 26.77 & 36.80 & 43.50 & 50.20 & $53.30 \mathrm{e}$ \\
\hline CON & 0.10 & 0.20 & 0.30 & 6.80 & 7.13 & 7.23 & $7.33 \mathrm{f}$ \\
\hline
\end{tabular}

Means in a column followed by different letters are significantly different $(P<0.05$, Tukey test)

NSS6 $=$ Neem seeds stored in the sun for six weeks

NSS4 $=$ Neem seeds stored in the sun for four weeks

NSS2 $=$ Neem seeds stored in the sun for two weeks

NSF6 $=$ Neem seeds stored in the refrigerator $\left(4^{\circ} \mathrm{C}\right)$ for six weeks

NSF4 $=$ Neem seeds stored in the refrigerator for four weeks

$\mathrm{NSF} 2=$ Neem seeds stored in the refrigerator for two weeks

NSRT6 $=$ Neem seeds stored at room temperature $\left(28 \pm 2^{\circ} \mathrm{C}\right)$ for six weeks

$\mathrm{CON}=$ Treated with water only

Table 3: Means percentage mortality of Tribolium castaneum pupae treated with extracts from neem seeds stored at different storage conditions and for different periods of time

\begin{tabular}{|c|c|c|}
\hline \multirow{2}{*}{ Treatment } & \multicolumn{2}{|c|}{ Per cent Mortality } \\
\cline { 2 - 3 } & $1^{\text {St }}$ & $7^{\text {th }}$ \\
\cline { 2 - 3 } & 18.35 & $49.67 \mathrm{a}$ \\
\hline NSS6 & 16.70 & $51.40 \mathrm{a}$ \\
\hline NSS4 & 11.70 & $54.77 \mathrm{a}$ \\
\hline NSS2 & 11.71 & $68.12 \mathrm{~b}$ \\
\hline NSF6 & 15.16 & $64.77 \mathrm{~b}$ \\
\hline NSF4 & 21.68 & $58.08 \mathrm{c}$ \\
\hline NSF2 & 10.12 & $69.43 \mathrm{~b}$ \\
\hline NSRT6 & 0.14 & $7.33 \mathrm{~d}$ \\
\hline CON & & \\
\hline
\end{tabular}

Means in a column followed by different letters are significantly different $(P<0.05$, Tukey test $)$

NSS6 $=$ Neem seeds stored in the sun for six weeks

NSS4 $=$ Neem seeds stored in the sun for four weeks

NSS2 $=$ Neem seeds stored in the sun for two weeks

NSF6 $=$ Neem seeds stored in the refrigerator $\left(4^{\circ} \mathrm{C}\right)$ for six weeks

NSF4 $=$ Neem seeds stored in the refrigerator for four weeks

$\mathrm{NSF} 2=$ Neem seeds stored in the refrigerator for two weeks

NSRT6 $=$ Neem seeds stored at room temperature $\left(28 \pm 2^{\circ} \mathrm{C}\right)$ for six weeks

$\mathrm{CON}=$ Treated with water only

\section{DISCUSSION}

Many researchers have demonstrated the effectiveness of neem for protecting vegetable crops in Sudan (Siddig, 1987, Elshafie and Basedow, 2003,
Mudathir and Basedow, 2003). This study has presented evidence that storage conditions and durations are among the many factors that affect the efficacy of neem seeds as biopesticides. Other factors include rainfall, soil type and other climatic conditions. EITeraifi (2004) demonstrated that the 
Azadirachtin content of neem seeds collected from different ecozones of the Sudan increased with the increase of rainfall.

Neem seeds stored in the sun both as intact and powder showed a decreasing trend of efficacy with increasing the storage period. The bio-efficacy of the neem seeds, as reflected by the larval and pupal mortality of the test insect, obtained with the neem seeds stored for only two weeks was greater than that stored for 4 and 6 weeks.

Neem is ideal for both conventional and IPM program and can be used throughout the entire crop production cycle. It can be dipped, drenched, mixed with liquid fertilizers in drip systems and applied with all spray equipment including thermal fog and ultra low volume systems. The increasing awareness about the potential of Neem and its importance need to be translated into actual economic and environmental benefits for the farmers. However, it must be realized that, for the production of a homemade neem insecticide, several important steps of work have to be done by the farmer (Hellpap and Dreyer, 1995). These include the selection of good quality neem fruits, proper depulping and drying of seeds to avoid the build-up of the potent carcinogen, aflatoxin $B_{1}$ (Chourasia and Roy, 1991), and finally proper storage. Neem can help reduce usage of chemical insecticides and more importantly can reduce overall insecticide usage, as Neem actually affects insects' tolerance to other insecticides and can make them more vulnerable at lower rates. The currently preferred active ingredient of Neem Azadirachtin has shown no evidence of insect resistance. Growers can use it with absolutely no fear of resistance when used either continuously or in combination with other insecticides. For ecologically sound, equitable, and ethical pest management, there is a need for control agents that are pestspecific, nontoxic to humans and other biota, biodegradable, less prone to pest resistance and resurgence, and relatively less expensive. Among various options, neem has been identified as a source of environmentally "soft" natural pesticides. A number of compounds in neem kernel extract have been shown to have bioactivity equal or greater to that of Azadirachtin A (Lin-er et al. 1995). Lower temperatures have been found to actually increase the efficacy of neem seeds 10-fold (Kabaru and Mwangi, 2000). We conclude that neem seeds can be stored in a shaded room for up to 2 months without significant reduction in overall effectiveness. Subsistence farmers in Sudan and other African countries with similar climatic conditions may be able to collect neem seeds at their convenience during the neem fruiting season, and store them in shaded rooms for at least 2 months. The stored seeds can be used later to prepare a cheap, effective, and environmentally friendly aqueous extract for protection of different crops.

\section{REFERENCES}

Anonymous, 2008. The genome of the model beetle and pest Tribolium castaneum, Nature vol. 452: 949955.doi:10.1038/nature06784.

Badi, K.H., Ahmed, A.E.H., Bayoumi, A.A.M.S., 1989. The forest of Sudan. Ministry of Agriculture, Khartoum, Sudan.

Binyanson, S.A. 1997. Comparison of three methods for establishing economic threshold levels for Jacobiasca lybica (de Berg) on eggplant. Ph.D. Thesis, University of Khartoum, Sudan.

Chourasia, H.K. and Roy, A.K. 1991. Effect of temperature, relative humidity and light on aflatoxin $B_{1}$ production in neem and Datura seeds. Int. J. pharmacognosy, 29: 197-202.

Dabrowski, Z.T., Alsaffar, A.A., Abdelrahman, A.A., 1994. Integrated pest management on vegetable crops in the Sudan, development and implementation strategy. In: Dabrowski, Z.T. (Ed.). integrated vegetable crop management in the Sudan. ICIPE Science Press, Nairobi, Kenya, (ISBN 92906440871), pp.24-32.

Dittrich, V., Ernst, G.H. Ruesch, o., Uk, S., 1990. Resistance mechanisms in sweet potato whitefly (Homoptera, Aleyrodidae) population from Sudan, Turkey, Guatemala and Nicaragua. J. Econom. Entomol. 83, 1665-1670.

Elshafie, H.A.F., 2001. The use of neem products for sustainable management of homopterous key pests on potato and eggplant in the Sudan. Ph.D. Thesis, University

Elshafie, H.A.F., Basedow, Th. 2003. The efficacy of different neem preparations for the control of insects damaging potatoes and eggplants in the Sudan. Crop protection, 22, 1015-1021.

EI-Teraifi, I.E. 2004. Variability in Growth, oil and limonoids in Neem (Azadirachta indica A. Juss) from different ecozones in Sudan, Ph.D. Thesis, Gezira University, Sudan.

Ermel, K. 1995. Azadirachtin contents of neem seed kernels from different regions of the world. In: Schmutterer, H. (Ed.). The neem tree. Source of Unique Natural products for Integrated Pest Management, Medicine, Industry and other purposes. Weinheim, New York, Basel, Cambridge, Tokyo (VCH), pp.89-92. 
Förster, P. and Moser, G. 2000. Status report on global neem usage. Universum Verlagsanstalt. 65175, Wiesbaden, GTZ, Eschborn, Germany, pp.8-28.

Hellpap, C. and Dreyer, M. 1995. The smallholder's homemade products. In: Schmutterer, H. (Ed.). The neem tree. Source of Unique Natural products for Integrated Pest Management, Medicine, Industry and other purposes. Weinheim, New York, Basel, Cambridge, Tokyo (VCH), pp. 367-375.

Jacobson, M., Reed, D.K., Crystal, M.M., Smorento, D.S. and Sonderstrom, E.L. 1987. Chemistry and biological activity of insect feeding deterrents from certain weed and crop plants. Entomologia Exp.Appl., 41: 248-257.

Jenkins, D.A., Dunkel, F.V., Gamby, K.T. 2003. Storage temperature of neem kernel extract: Differencial effects on oviposition deterrency and larval toxicity of Callosobruchus maculatus (F.) (Coleoptera: Bruchidae). Environ. Entomol. 32(6): 1283-1289.

Kabaru, J.M. and Mwangi, R.W. 2000. Effect of posttreatment temperature on the insecticidal activity of neem, (Azadirachta indica A.Juss) seed extract on Schistocerca gregaria (Forskal): a preliminary report. Insects Sci. Appl. 20: 77-79.

Kumar, L. and Parmar, B.S. 1999. Stabilization of Azadirachtin $A$ in neem formulations: Effect of some solid carriers, neem oil, and stabilizers. J. Agric. Food Chem. 47: 1735-1739.

Ladd, T.L., Jacobson, M. and Buriff, C.R. 1978. Japanese plants extracts from Neem tree seeds as feeding deterrents. J.Econ.Ent. 71:810-813.

Lange, W. 1984. Piperonyl butoxide; synergistic effects on different neem seed extracts and influence on degradation of an enriched extract by ultra-violet light. Proc. $\quad 2^{\text {nd }} \quad$ Int. Neem Conf., Rauischholzhausen,Germany,. pp.123-139.
Leuschner, K. 1972. Effect of an unknown plant substance on a shield bug. Naturewissenschaften, 29:217-218.

Lin-er, L., Van Loon, J.J.A. and Schoonhoven, L.M. 1995. Behavioural and sensory responses to some neem compounds by Pieris brassicae larvae. Physiol. Entom. 20: 134-140.

Mudathir, M. and Basedow, Th. 2003. Field experiments on the effects of neem products on pests and yield of okra Abelmoschus esculentus, Tomato, Lycopersicon esculentum and onion, Allium cepa in Sudan. Mitt. Deut. Ges. Allg. Angew. Entomol. 14: 407-410.

Schmutterer, H. and Ascher, K.R.S. 1987. Natural pesticides from the neem tree (Azadirachta indica A. Juss) and other tropical palnts. Proceeding of the $3^{\text {rd }}$ international neem conference, Nairobi, Kenya, 10-15 July 1986. Eschborn, Germany.

Schmutterer, H. and Hübner, J. (Eds.) 2005. Natürliche Schädlingsbekämpfungsmittel, Eugen Ulmer $\mathrm{GmbH}$ and Co. pp.263.

Siddig, A.S. 1987. A proposed pest management program including neem treatment for combating potato pests in the Sudan. In: Schmutterer, H., Ascher, K.R.S. (Eds.), natural pesticides from the neem tree and other tropical plants. Proceedings of the Third International neem Conference. GTZ, Eschborn, Germany, Nairobi, 1986, pp.449-459.

Sokoloff, A. 1977. The biology of Tribolium with special emphasis on genetic aspect 1-111 (Clarendon Press and Oxford Uni. Press. Oxford)

Strokes, J.B. and Redfern, R.E. 1982. Effect of sunlight on Azadirachtin: antifeeding potency. J. Envir. Sci. HIth. A. 17: 57-65 